\title{
Intelligent Control for the BEES Flyer
}

\author{
K. Krishnakumar", Karen Gundy-Burlet", Mike Aftosmis \\ Marian Nemec ${ }^{\S}$, \\ Greg Limes $^{* *}$, Misty Berry ${ }^{*}$, Michael Logan \\ NASA Ames Research Center \\ Moffett Field, CA 94035
}

\begin{abstract}
This paper describes the effort to provide a preliminary capability analysis and a neuralnetwork based adaptive flight control system for the JPL-led BEES aircraft project.

The BEES flyer was envisioned to be a small, autonomous platform with sensing and control systems mimicking those of biological systems for the purpose of scientific exploration on the surface of Mars. The platform is physically tightly constrained by the necessity of efficient packing within rockets for the trip to Mars. Given the physical constraints, the system is not an ideal configuration for aerodynamics or stability and control. The objectives of this effort are to evaluate the aerodynamics characteristics of the existing design, to make recommendations as to potential improvements and to provide a control system that stabilizes the existing aircraft for nominal flight and damaged conditions. Towards this several questions are raised and analyses are presented to arrive at answers to some of the questions raised.

CART3D, a high-fidelity inviscid analysis package for conceptual and preliminary aerodynamic design, was used to compute a parametric set of solutions over the expected flight domain. Stability and control derivatives were extracted from the database and integrated with the neural flight control system. The Integrated Vehicle Modeling Environment (IVME) was also utilized for estimating aircraft geometric, inertial, and aerodynamic characteristics.

A generic neural flight control system is used to provide adaptive control without the requirement for extensive gain scheduling or explicit system identification. The neural flight control system uses reference models to specify desired handling qualities in the roll, pitch, and yaw axes, and incorporates both pre-trained and on-line learning neural networks in the inverse model portion of the controller. Results are presented for the BEES aircraft in the subsonic regime for terrestrial and Martian environments.
\end{abstract}

\footnotetext{
"Scientist, NASA Ames Research Center, MS 269-1, Moffett Field, CA 94035-1000, Associate Fellow

'Scientist, NASA Ames Research Center, MS 269-3, Moffett Field, CA 94035-1000, Associate Fellow

Scientist, NASA Ames Research Center, MS T27B, Moffett Field, CA 94035-1000,-Senior Member

$\$$ NRC Research Associate, NASA Ames Research Center, MS 269-1, Moffett Field, CA 94035-1000

** Software Engineer, QSS Inc, NASA Ames Research Center, MS 269-1, Moffett Field, CA 94035-1000

Engineer, QSS Inc, NASA Ames Research Center, MS 269-1, Moffett Field, CA 94035-1000

Engineer, QSS Inc, NASA Ames Research Center, MS 262-6, Moffett Field, CA 94035-1000
} 


\section{Introduction}

Fast-moving airpianes designed to navigate Mars the way insects control their courses on Earth might one day travel to places where exploration rovers and landers cannot reach. Mars is covered with intriguing canyons, cliffs, and craters, most of them too remote or hazardous for conventional exploration vehicles. Exploration Air Vehicles (EAVs) could carry cameras and other sensors to these spots. Building a Mars EAV will provide a new way for NASA to conduct exploration. In addition to exploration of hard to reach spaces, EAVs could relay information between rovers already exploring the planet's surface or monitor a spacecraft while it touches down.

The JPL-led Mars EAV project is named BEES, for Bio-inspired Engineering of Exploration Systems, and has been in the works for a few years [1,2]. The plane is called a biomorphic flyer because it captures some of nature's successful filight designs-in this case, unique sürategies of navigation, hazard avoidance and flight--and combines them with conventional designs. The BEES technology is based on the fact that insects like the honeybee and the dragonfly possess a brain with less than 0.01 percent the neurons found in a human brain, yet with simple strategies they navigate in the world just fine.

Putting a plane on Mars poses several challenges. For one, the atmosphere on Mars is so thin that flying an aircraft near the surface is difficult, like trying to control a plane 100,000 feet above the Earth's surface. And because Mars is mostly unexplored, an unpiloted aircraft would need to have the ability to sense and respond to what it encounters.

The work reported in this paper examines software based on an adaptive neural network to control the BEES EAV's attitude in the midst of uncertainties and failures.

\section{Test Article}

The current BEES flyer is shown in Figure 1. The aircraft is a delta-type wing flyer with twin vertical tails for stabilization. Two elevons are utilized for control of the aircraft. Information for the $5 \mathrm{~kg}$ biomorphic flyer was utilized in this effort. The values are referenced below:

Table 1: Test Article (5 kg, 02 Biomorphic Flyer) Details

\begin{tabular}{|l|l|l|l|}
\hline Item & & & \\
\hline Dry Mass & $2670 \mathrm{~g}$ & Landing Speed & $\approx 55 \mathrm{~km} / \mathrm{h}$ \\
\hline Fuel & $340 \mathrm{~g}$ & Range & $55000 \mathrm{~m}$ \\
\hline Payload & $1990 \mathrm{~g}$ & Endurance & $>20 \mathrm{~min}$ \\
\hline Takeoff weight & $5000 \mathrm{~g}$ & Wing Span & $1.240 \mathrm{~m}$ \\
\hline Engine & $698 \mathrm{~g}$ & MAC & $0.606 \mathrm{~m}$ \\
\hline Propeller & $58 \mathrm{~g}$ & $\begin{array}{l}\text { Leading edge sweep } \\
\text { back }\end{array}$ & $50.8^{\circ}$ \\
\hline Engine Type & OS $61 \mathrm{FX}$ & Aspect Ratio & 2.206 \\
\hline Propeller Size & $28.0 \mathrm{~cm} \times 20 \mathrm{~cm}$ & Taper Ratio & 0.19 \\
\hline Top Speed & $\approx 165 \mathrm{~km} / \mathrm{h}$ & Wing Area & $0.701 \mathrm{~m}^{2}$ \\
\hline
\end{tabular}




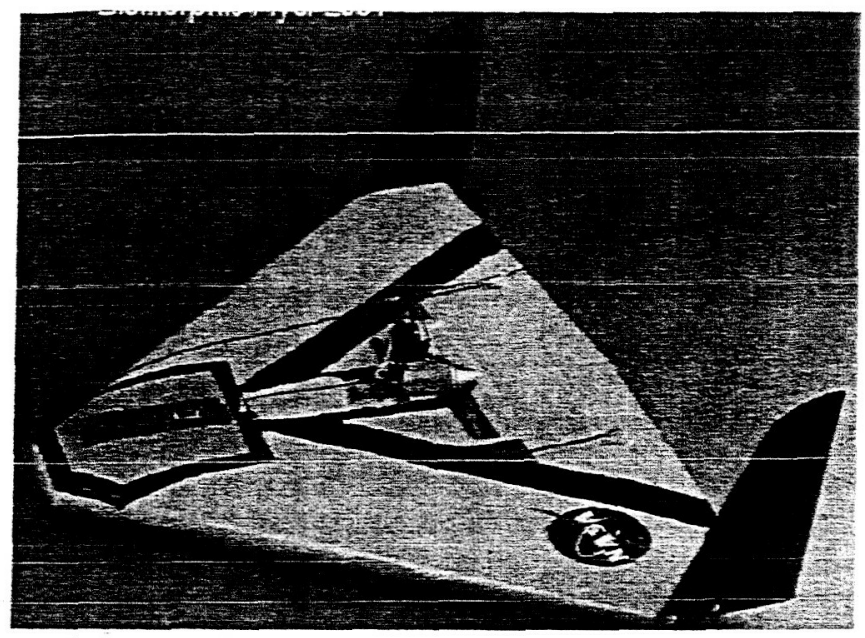

Figure 1: The BEES Platform

\section{Modeling Using CART3D}

CART3D is a high-fidelity inviscid analysis package for conceptual and preliminary aerodynamic design [3. 4]. It allows users to perform automated CFD analysis on complex geometry. The package includes utilities for geometry import, surface modeling and intersection, mesh generation and flow simulation. Currently the package includes two flow simulation codes: Tiger, and flowCart. The package is highly automated so that geometry acquisition and mesh generation can usually be performed within a matter of minutes on most modern UNIX workstations or PC's.

Geometry comes into the package in the form of surface triangulations which can be generated from many popular $C A D$ packages, from legacy surface triangulations or from structured surface grids. CART3D uses adaptively refined Cartesian grids to discretize the space surrounding a geometry and cuts the geometry out of the set of "cut-cells" which actually intersect the boundary. The flow solvers run on single and multiprocessor computing platforms.

A Pro-E solid model of the BEES aircraft was provided by Australian National University (ANU) as the basis for this effort. Substantial efforts were involved in removing features (such as the engine and holes for the actuation devices) and in making the geometry "water-tight. The engine cowling was modified to provide a complete seal against the body. The slot for the propeller was not faired over for this effort. Figure 2 shows a sample of the CAD geometry as generated by the Pro-E solid modeler. A view of a representative grid of the final geometry is provided in Figure 3 and demonstrates the locally adaptive Cartesian nature of the grids utilized by CART3D. Looking carefully at Figure 3, it can be seen that the geometry contains significant surface waviness up to about $20 \%$ of chord which could affect some features of the aerodynamic field. 


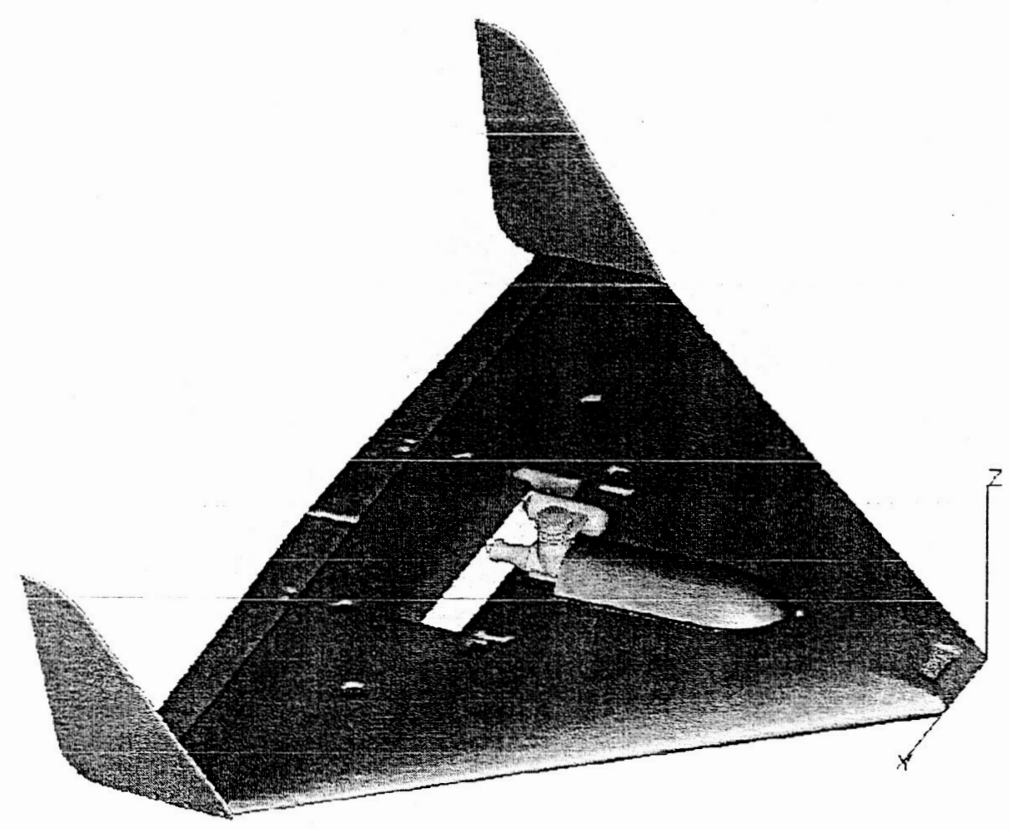

Figure 2. BEES CAD Model - First Cut

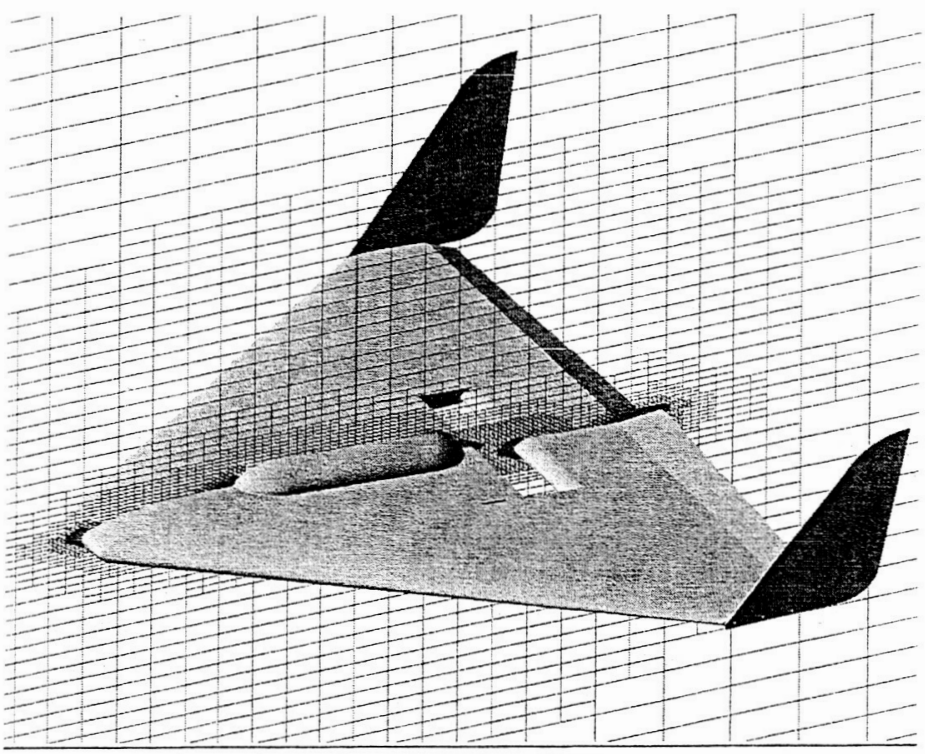

Figure 3. Cartesian Grid Section on Computational Geometry for Fully Deflected Elevons.

\subsection{Results Using CART3D}

The analysis using CART3D generated 4704 cases for the following combinations of flight variables: Mach \# = 0.2, 0.3, 0.4, 0.5, 0.6, 0.7, 0.75, 0.8

Angle-of-attack $=-10,-5,0,5,10,15$ degrees

Side Slip Angle $=0,-10$ degrees

Elevon Deflection $=49$ different cases (each elevon at $-10,-5,0,5,10,15$ and 20 degrees); 
Surface pressure data was integrated to provide forces and moments on the delta wing, stabilizers and control surfaces of the BEES flyer. These were used to analyze and answer the fundamental question: Will the BEES Fyer fly at subsonic speeds in Mars?

Figures 4 through 7 document several of the aerodynamic curves of interest.

Given the plots, one can compute the velocity needed to hy level, non-accelerating flight at different positive angles-of-attack.

Table 2: Mach \# and Thrust Required for Level Flight

\begin{tabular}{|c|c|c|c|}
\hline \multicolumn{4}{|c|}{$\begin{array}{l}\text { Given: } \\
\begin{array}{l}\text { Mass of Flyer }(\mathrm{m})=5 \mathrm{~kg} \\
\text { Gravity on Mars }\left(\mathrm{g}_{\mathrm{M}}\right)=1 / 3 \text { of Earth gravity }\left(\mathrm{g}_{\mathrm{E}}\right) \\
\rho=\text { Density on Mars at "sea level" }=0.015 \mathrm{~kg} / \mathrm{m}^{3} \\
\mathrm{a}_{\infty}=\text { Speed of sound on Mars }=268 \mathrm{~m} / \mathrm{s} \\
\mathrm{S}=\text { surface area }=0.7 \mathrm{~m}^{2} \\
C_{L}=\text { Coefficient of lift } \\
C_{\mathrm{D}}=\text { Coefficient of drag } \\
\mathrm{L}=\text { Lifting force } \\
D=\text { Drag } \\
W=\text { Weight of craft on Mars }=\mathrm{mg} \\
\mathrm{T}=\text { Engine thrust } \\
\alpha=\text { Angle of attack } \\
V=\text { Forward airspeed }\end{array}\end{array}$} \\
\hline \multicolumn{4}{|c|}{$\begin{array}{l}\text { Assumptions: } \\
\text { No wind or turbulence } \\
\text { Thrust required is to maintain level flight only }\end{array}$} \\
\hline $\begin{array}{l}\text { Angle-of-attack } \\
\text { (deg) }\end{array}$ & Velocity $(\mathrm{m} / \mathrm{s})$ & Mach \# & Thrust Required (N) \\
\hline 5 & 122.18 & 0.46 & 0.71 \\
\hline 10 & 83.88 & 0.31 & 1.55 \\
\hline 15 & 69.67 & 0.26 & 2.57 \\
\hline
\end{tabular}




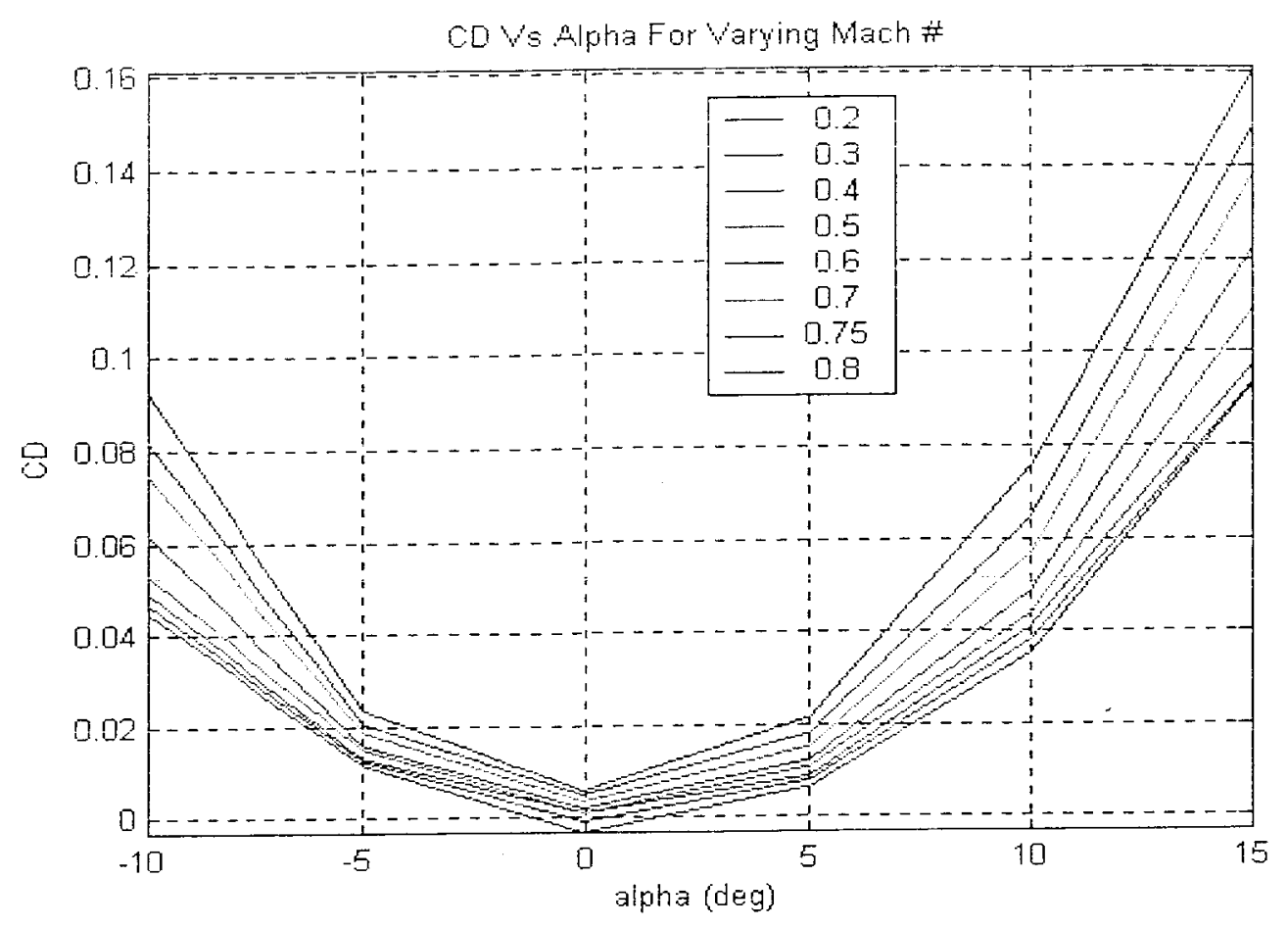

Figure 4. $C_{D}$ Versus Alpha for Varying Mach \#

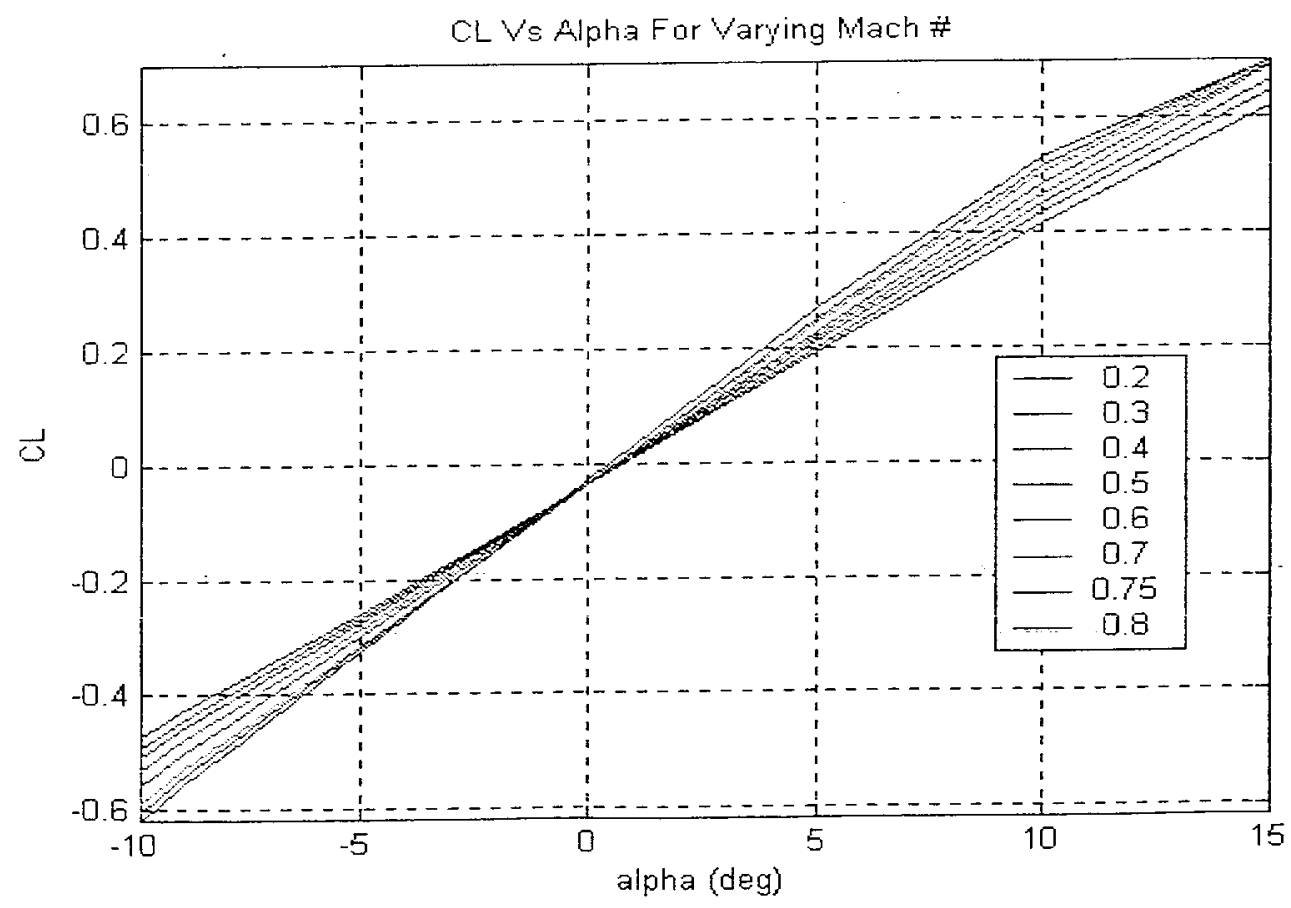

Figure 5. $C_{L}$ Versus Alpha for Varying Mach \#

6

American Institute of Aeronautics and Astronautics 


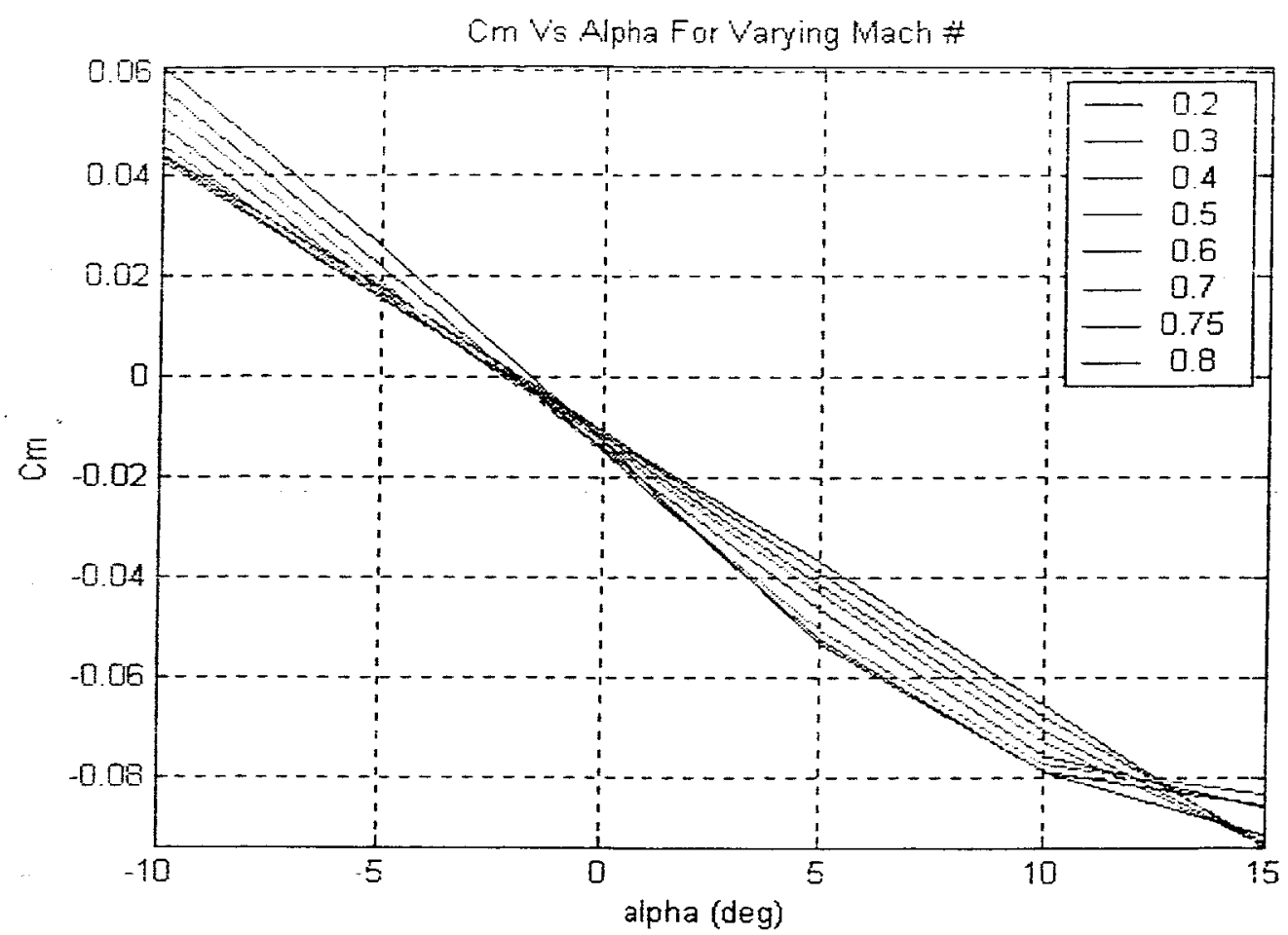

Figure 6. $C_{m}$ Versus Alpha for Varying Mach \#

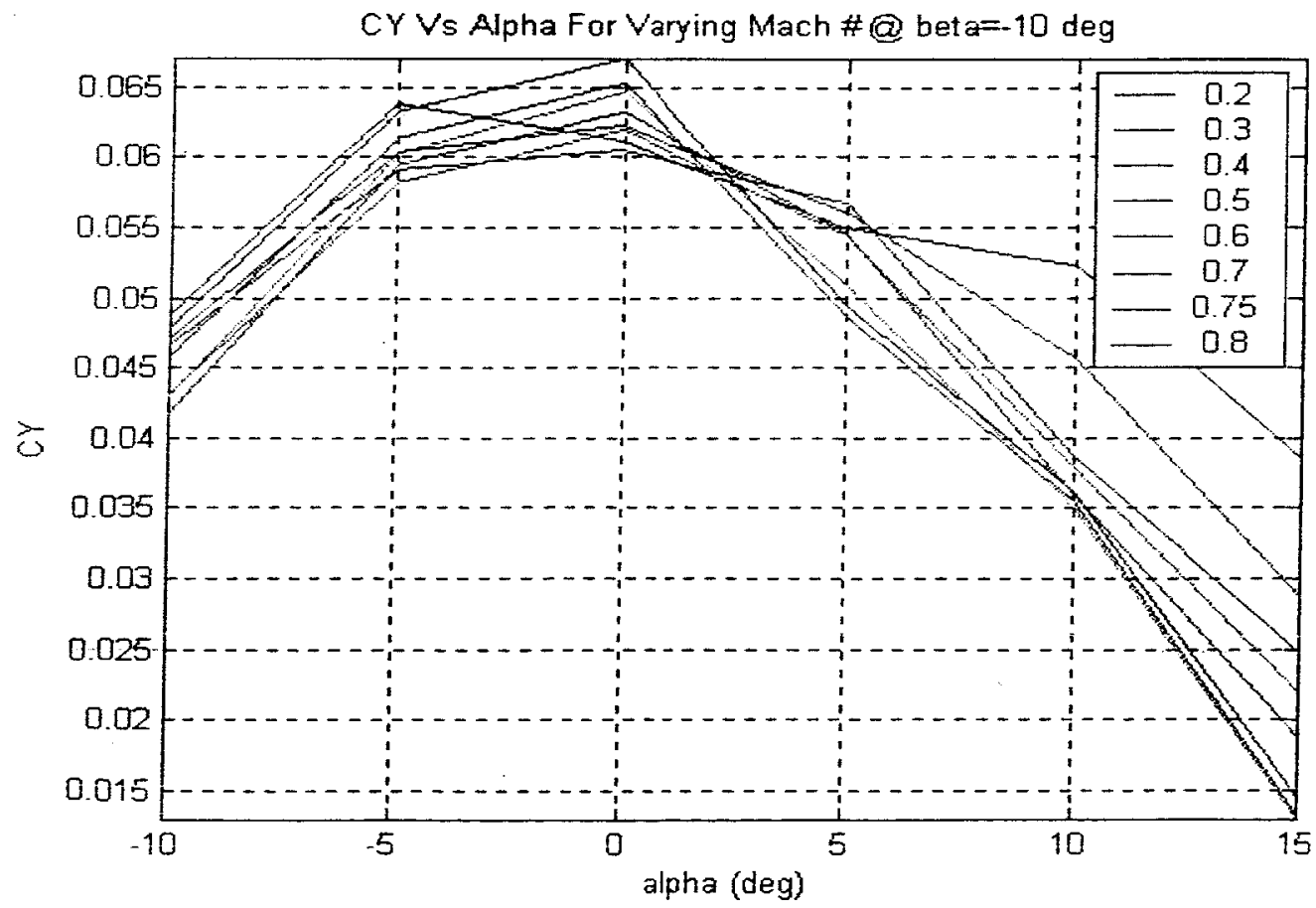

Figure 7. $C_{Y}$ Versus Alpha for Varying Mach \# 
By examining the data presented, one can conclude the following:

a. The BEES flyer can fly at low angles of attack in the subsonic regime with no needed modifications.

b. The drag rise for Mach $>0.7$ is quite severe even at moderate angles of attack. This problem could be alleviated by either avoiding the transonic regime, or preferably , by modifying the design. A small change in the airfoil could result in a significant reduction in drag in the transonic regime.

c. The engine casing and the hole behind it distorts the flow significantly. This needs to be redesigned. The initial estimate of control authority seems sufficient for nominal flight conditions.

d. Sensor locations have to be chosen to minimize the effects of the flow.

\subsection{Extensions to the Model to Include Rotational Effects}

The CART3D solutions generated for this study are steady in time and thus don't directly permit the computation of stability and control derivatives with respect to the pitch, roll and yaw rates of the aircraft. Unsteady solutions can be generated but take significantly more computational resources. An approximation to these derivatives can be formed by assuming that the effect of rotation is dominated by the change in flow angle relative to the body as one moves away from the center of gravity. For the pitch and roll axes, the effect would then be dominated by the derivative with respect to angle of attack:

$$
\begin{aligned}
& {\left[\begin{array}{l}
C x_{p} \\
C y_{p} \\
C z_{p}
\end{array}\right] \approx \sum_{i=1}^{N_{l_{S}}} \frac{y_{i}}{l} \frac{d C p_{i}}{d \alpha_{i}} \frac{d A_{i}}{S} \vec{n}_{i}} \\
& {\left[\begin{array}{l}
C l_{p} \\
C m_{p} \\
C n_{p}
\end{array}\right] \approx \sum_{i=1}^{N i_{S}} \frac{r_{i}}{l} \times\left(\frac{y_{i}}{l} \frac{d C p_{i}}{d \alpha_{i}} \frac{d A_{i}}{S}\right) \vec{n}_{i}} \\
& {\left[\begin{array}{l}
C x_{q} \\
C y_{q} \\
C z_{q}
\end{array}\right] \approx \sum_{i=1}^{N i_{S}} \frac{x_{i}}{l} \frac{d C p_{i}}{d \alpha_{i}} \frac{d A_{i}}{S} \vec{n}_{i}} \\
& {\left[\begin{array}{l}
C l_{q} \\
C m_{q} \\
C n_{q}
\end{array}\right] \approx \sum_{i=1}^{N i_{S}} \frac{r_{i}}{l} \times\left(\frac{x_{i}}{l} \frac{d C p_{i}}{d \alpha_{i}} \frac{d A_{i}}{S}\right) \vec{n}_{i}}
\end{aligned}
$$

And for the yaw axis, it is assumed that the primary effect will be the sideslip of the vertical surfaces relative to the freestream: 


$$
\begin{aligned}
& {\left[\begin{array}{l}
C x_{p} \\
C y_{p} \\
C z_{p}
\end{array}\right]=\sum_{i=1}^{N i_{s}} \frac{y_{i}}{l} \frac{d C p_{i}}{d \beta_{i}} \frac{d A_{i}}{S} \vec{n}_{i}} \\
& {\left[\begin{array}{l}
C l_{p} \\
C m_{p} \\
C n_{p}
\end{array}\right] \approx \sum_{i=1}^{N i_{S}} \frac{r_{i}}{l} \times\left(\frac{y_{i}}{l} \frac{d C p_{i}}{d \beta_{i}} \frac{d A_{i}}{S}\right) \vec{n}_{i}}
\end{aligned}
$$

\section{Intelligent Flight Control System}

Figure 8 presents the implementation of a Level 1 Intelligent Controller for the BEES test bed developed in this study. It should be noted that Level 0 is non-adaptive whereas Level 1 is adaptive. The generic neural flight control system is based on the augmented model inversion architecture developed by Rysdyk and Calise [11]. This direct adaptive tracking controller integrates feedback linearization theory with both pretrained and on-line leaming neural networks. Details of the architecture are given below.

Reference Models: The autopilot commands roll and pitch rates and aerodynamic lateral accelerations through elevon and rudder inputs. These commands are then transformed into body-axis rate commands, which also include turn coordination, level turn compensation, and yaw-dampening terms. First-order reference models are used to filter these commands in order to shape desired handing qualities.

P + I Error Controller (Level 0): Errors in roll rate, pitch rate, and yaw rate responses can be caused by inaccuracies in aerodynamic estimates and model inversion. Unidentified damage or failures can also introduce additional errors. In order to achieve a rate-command-attitude-hold (RCAH) system, a proportional-integral (PI) error controller is used to correct for errors detected from roll rate, pitch rate, and yaw rate $(p, q, r)$ feedback.

Learning Neural Network (Level 1): The on-line learning neural networks work in conjunction with the error controller. By recognizing patterns in the behavior of the error, the neural networks can learn to remove biases through control augmentation commands. These commands prevent the integrators from having to windup to remove error biases. By allowing integrators to operate at nominal levels, the neural networks enable the controller to provide consistent handling qualities. The learning neural networks not only help control the nominal system, but also provide an additional potential for adapting to changes in aircraft dynamics due to control surface failures or aüframe damage.

Dynamic Inversion/Aero Generation: The dynamic inversion element converts the summed response commands into virtual control surface commands. Dynamic inversion is based upon feedback linearization theory. No gain-scheduling is required, since gains are functions of aerodynamic stability and control derivative estimates and sensor feedback. Several methods are available to accomplish approximate model definition: simple linear model methods, nonlinear tables or using pre-trained neural networks (non-adapting) to provide estimates of aerodynamic stability and control characteristics. The model is then inverted to solve for the necessary control surface commands. In our work, a Levenberg-Marquardt (LM) multi-layer perceptron is used to provide dynamic estimates for model inversion. The LM network is pre-trained with stability and control derivative data generated by a Rapid Aircraft Modeler, and vortex-lattice code [5]. 


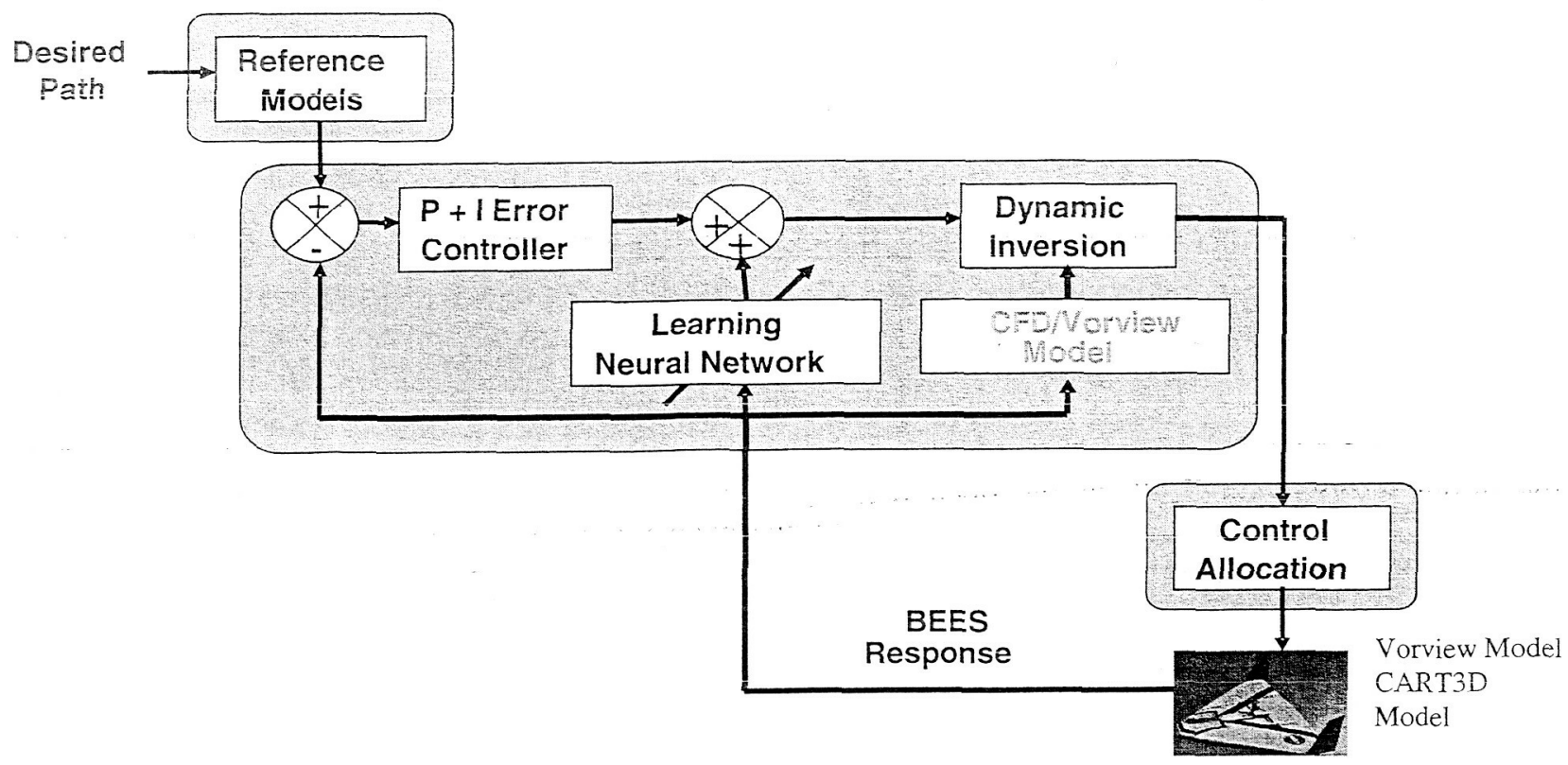

Figure 8. Intelligent Flight Control Architecture

\section{Results and Discussion}

Results are documented for the following cases:

- Mars and Earth scenarios with open-loop control and IFC system

- Control redundancy options with open-loop control and IFC system

- Two elevons and no rudder

- Four elevons with no rudder

- Failure cases with open-loop control and IFC system

- Failed elevons (all combinations)

- Longitudinal and lateral CG shift

Figure 9 presents roll and pitch doublet data for the BEES flyer in both Earth and Mars atmospheres at 0.5 Mach number for both an open loop control and the neural flight control system. Yaw data is not presented because without rudder panels, the yaw response of the aircraft cannot be directly controlled. These doublets were generated using the perturbation equation option of the FLTz code. As can be seen in the figure, the aircraft response in Earth's atmosphere is generally well behaved for both open-loop and IFC control systems. In the Mars atmosphere, undamped oscillations greatly affect the command tracking for both pitch and roll response in the open loop case. For the IFC controller, the aircraft response is reasonably consistent between the two environments. Figure 10 presents similar data for a 4 elevon configuration with no failures. The response characteristics are similar to those of the two elevon case.

The first of the failure cases presented in Figure 11 is that of a two elevon configuration with the left elevon jammed. With one of the two available control surfaces failed, independent control of pitch and roll rates is no longer possible. Apparent stability on Earth (left plots) depends strongly on starting in a trim condition. The immediate divergence in roll when a pitch input is applied in the Mars open loop case may not be immediately obvious. IFC fights to retain control, but the best it can achieve is a trade between pitch and roll rates. In Figure 12, a four elevon case with the left outboard elevon failed is considered. Splitting the control surfaces gives the error controller the opportunity to regain and maintain control after a single actuator 
failure. Note the early termination of the simulation in the open loop cases as the craft tumbles through attitudes outside the simulation domain.

In Figure 13, a longitudinal CG shift is imposed on the two elevon configuration. The longitudinal CG shift changes the pitch response of the system; in this case, the CG moved toward the rear of the craft by 5\% of the MAC. The open loop response on Earth shows increased pitch response, which is damped back down to reference levels by the error controller. The open loop response on Mars shows increased instability. Note that despite the large initial response to the doublet, IFC brings this condition back under control. In Figure 14 , the same longitudinal . CG shift is applied to the four elevon configuration. Splitting the control surfaces neither improves nor degrades system response to longitudinal CG shift.

The two elevon configuration with a lateral $C G$ shift failure is shown in Figure 15. The lateral $C G$ shift induces a huge coupling from the longitudinal control into the lateral response axis, as can be seen by the-initial response on Earth of the open loop system to a pitch input. The error controller brings this response back under control. The Martian conditions exacerbate the instability of the system. The error controller works in both environments to counteract the coupling, bringing the rate back under control and largely returning the attitude (not shown) to expected values. Early termination of the open loop simulations was due to the tumbling of the craft through attitudes outside the domain of the simulation; the transient at 41 seconds in the IFC earth case was a controlled descent through the terrain. The four elevon lateral CG shift case is shown in Figure 16.

Splitting the control surfaces neither improves nor degrades system response to a lateral CG shift. 

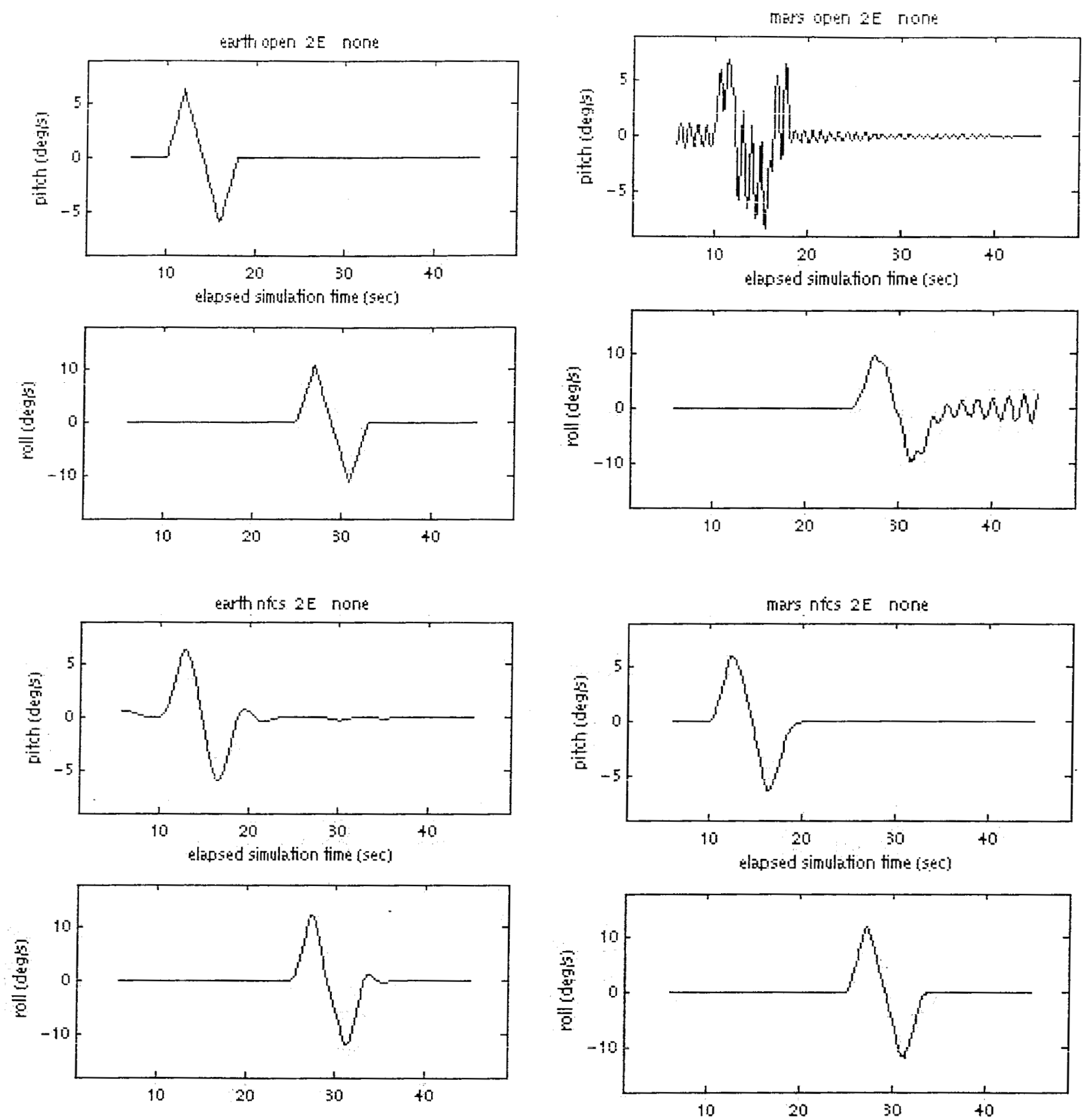

TOP LEFT: $\quad$ Earth open loop; TOP RIGHT: Mars open loop BOTTOM LEFT: Earth with IFC; BOTTOM RIGHT: Mars with IFC

Figure 9. Aircraft Response Doublets for Two Elevon Configuration. No Failures. 

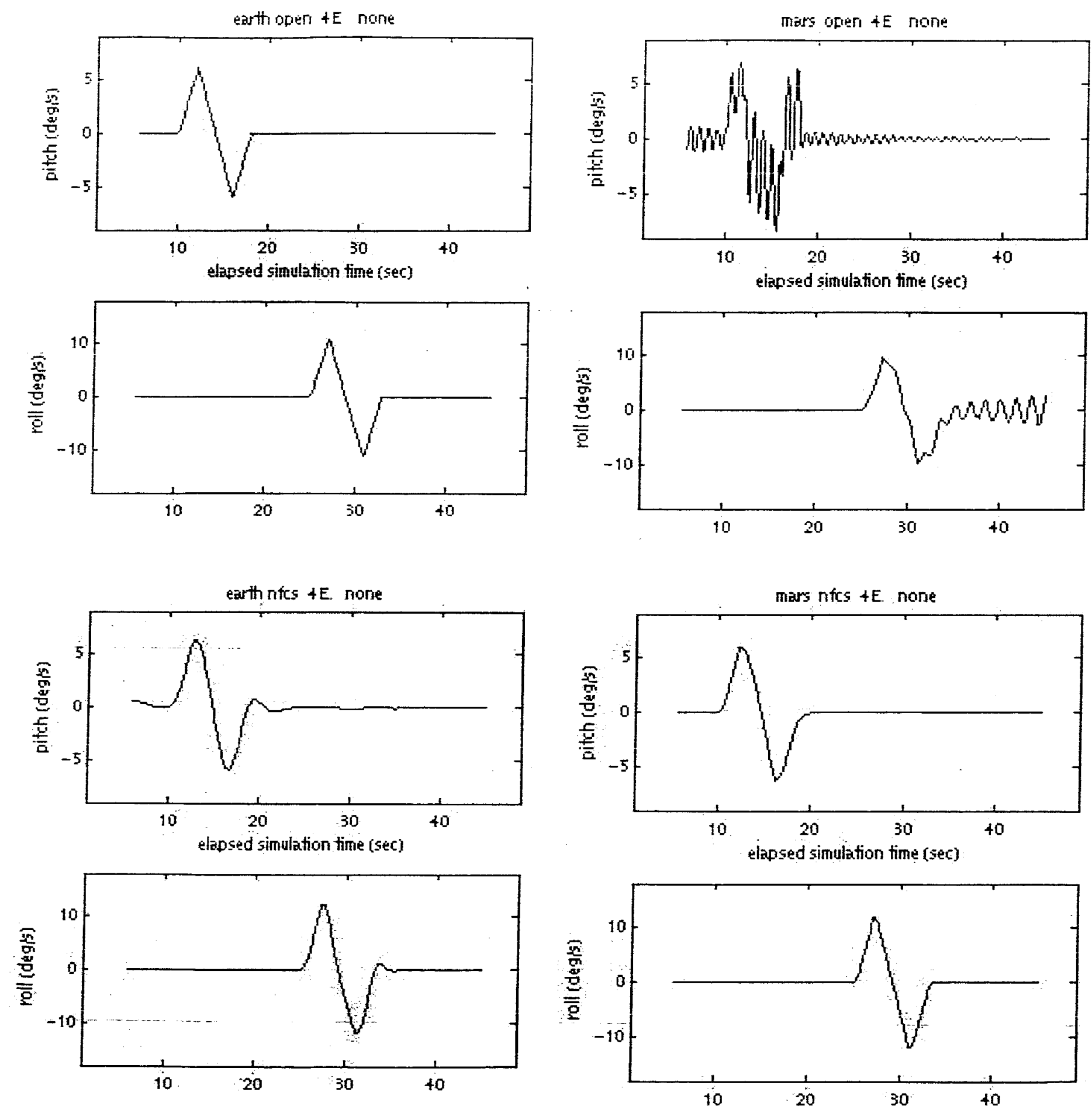

TOP LEFT: $\quad$ Earth open loop; TOP RIGHT: Mars open loop BOTTOM LEFT: Earth with IFC; $\quad$ BOTTOM RIGHT: Mars with IFC

Figure 10. Aircraft Response Doublets for Four Elevon Configuration. No Failures. 

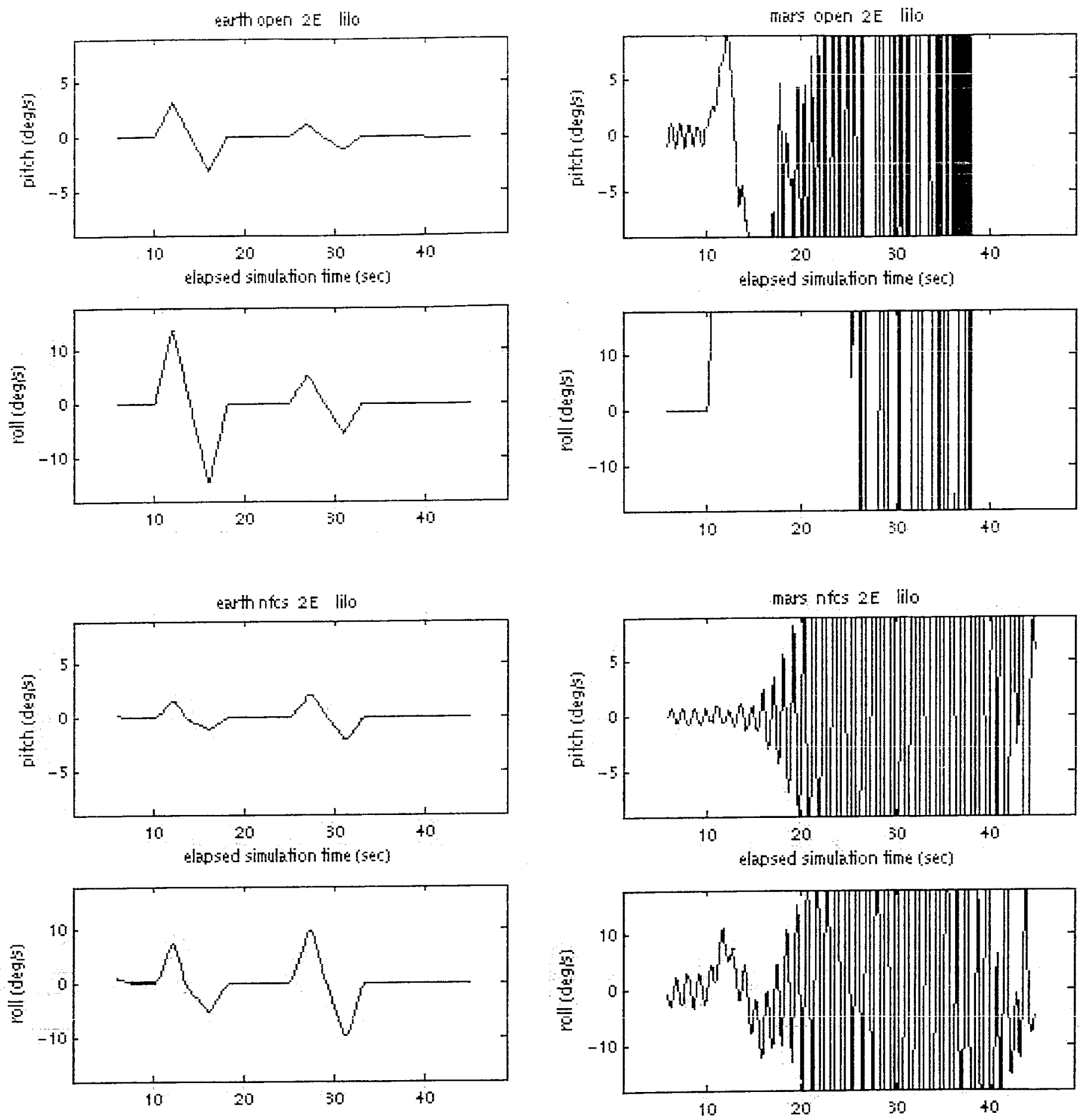

TOP LEFT: $\quad$ Earth open loop; TOP RIGHT: $\quad$ Mars open loop BOTTOM LEFT: Earth with IFC; $\quad$ BOTTOM RIGHT: Mars with IFC

Figure 11. Aircraft Response Doublets for Two Elevon Configuration Left Elevon Failed. 

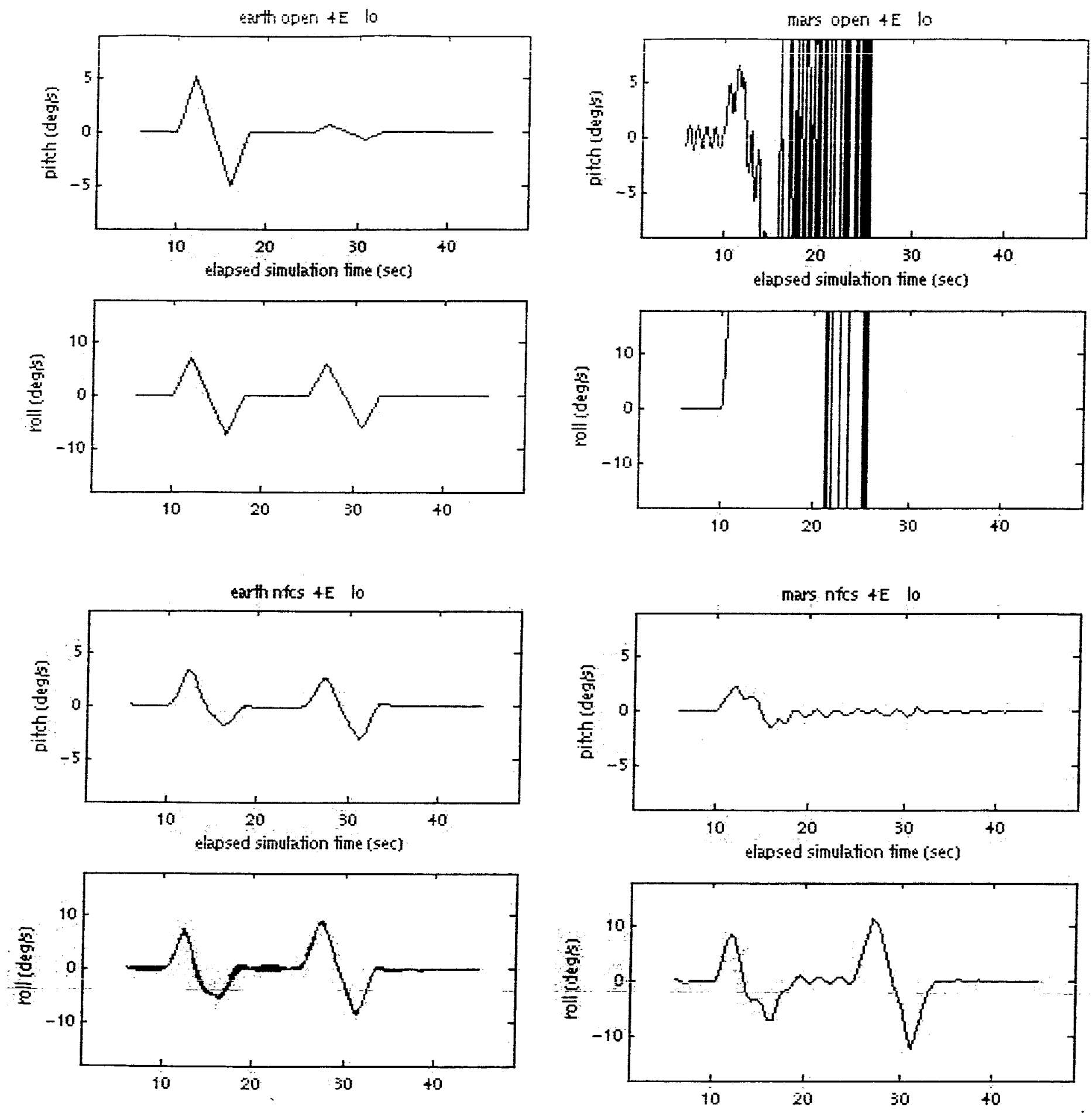

\section{TOP LEFT: $\quad$ Earth open loop; TOP RIGHT: $\quad$ Mars open loop} BOTTOM LEFT: Earth with IFC; $\quad$ BOTTOM RIGHT: Mars with IFC

Figure 12. Aircraft Response Doublets for Two Elevon Configuration. Left Outboard Elevon Failed. 

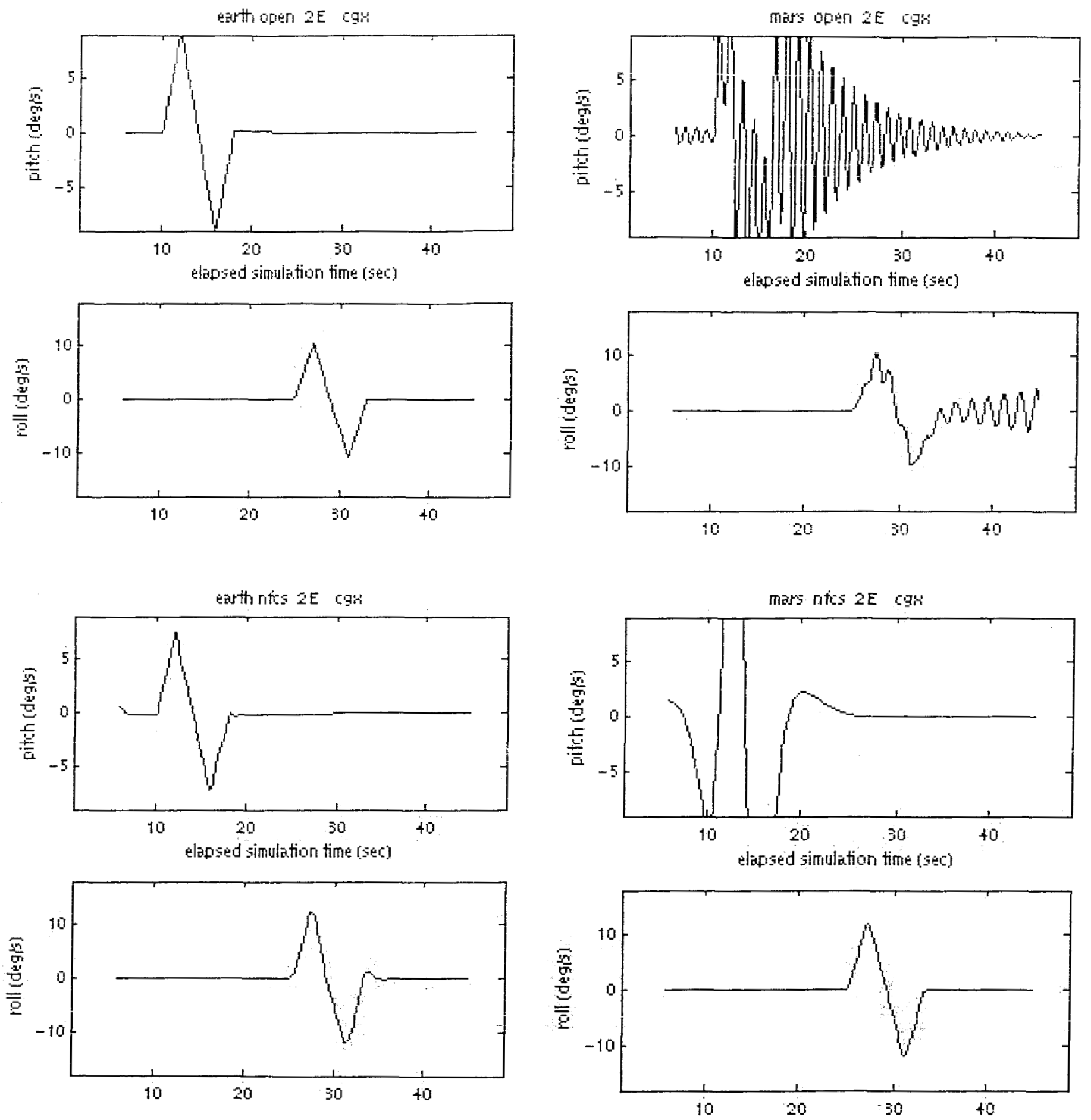

TOP LEFT: $\quad$ Earth open loop; TOP RIGHT: Mars open loop BOTTOM LEFT: Earth with IFC; $\quad$ BOTTOM RIGHT: Mars with IFC

Figure 13. Aircraft Response Doublets for Two Elevon Configuration. Longitudinal CG Shift 

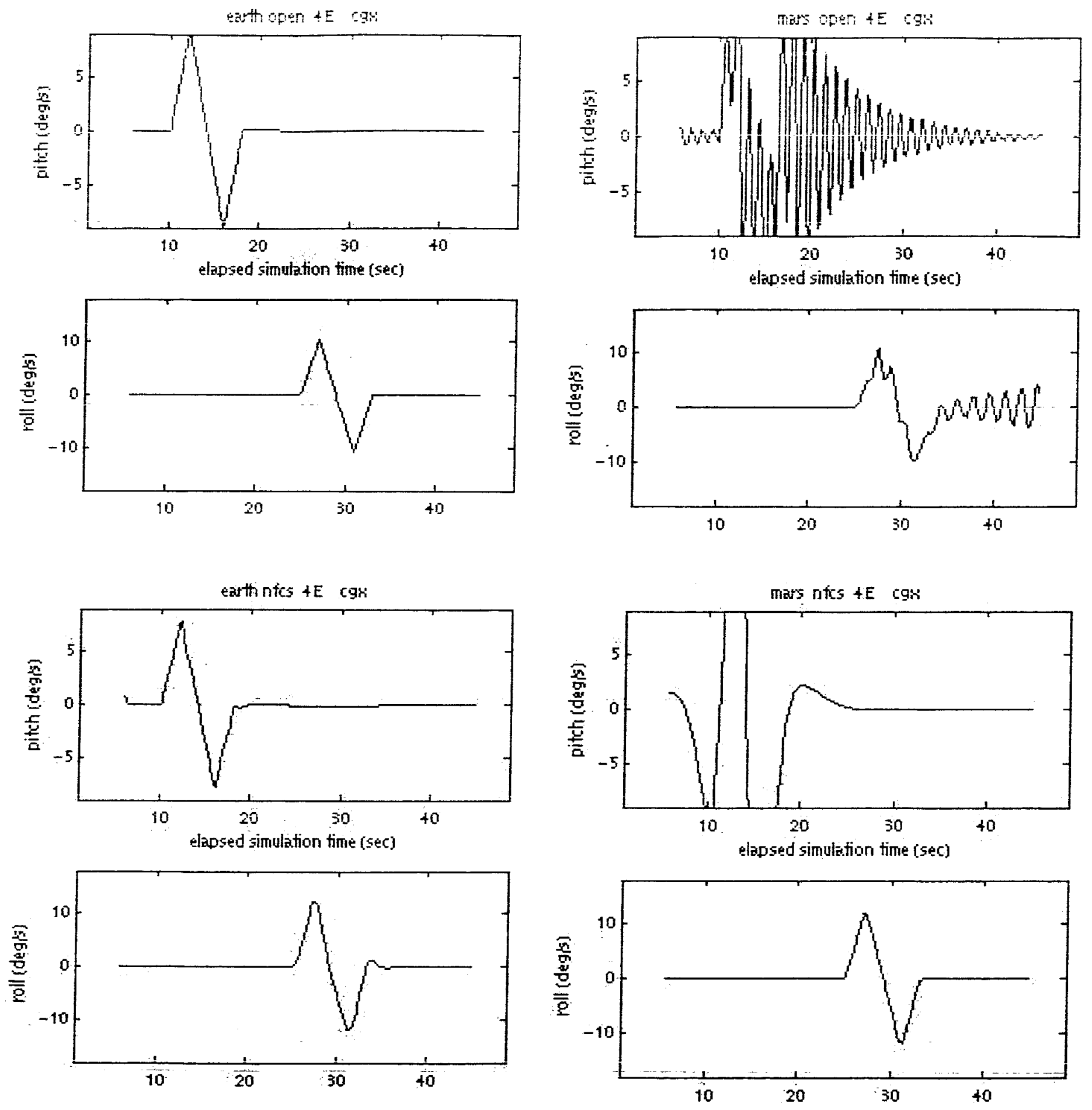

TOP LEFT: $\quad$ Earth open loop; TOP RIGHT: Mars open loop BOTTOM LEFT: Earth with IFC; BOTTOM RIGHT: Mars with IFC

Figure 14. Aircraft Response Doublets for Four Elevon Configuration. Longitudinal CG Shift. 

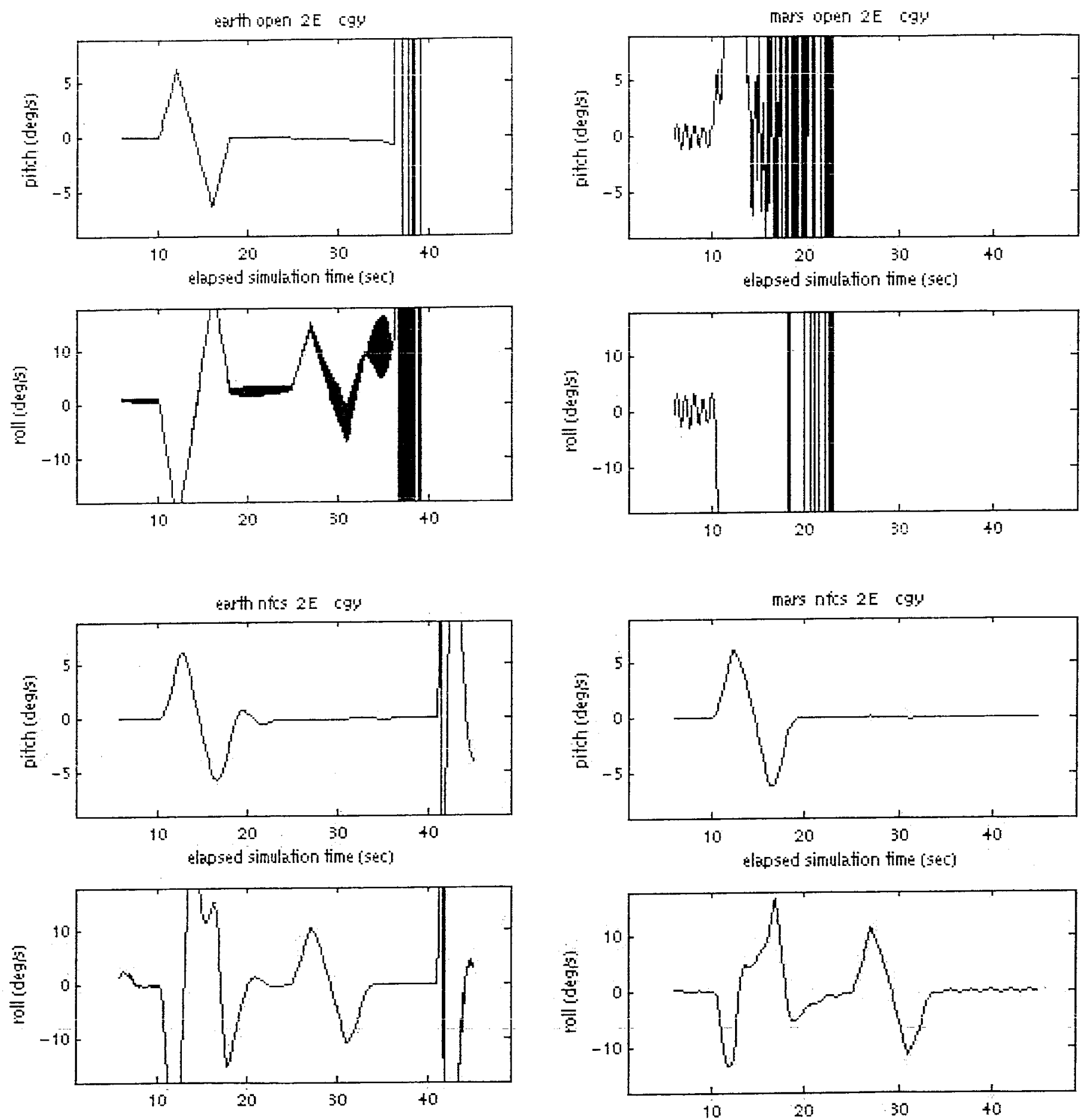

TOP LEFT: $\quad$ Earth open loop; TOP RIGHT: $\quad$ Mars open loop BOTTOM LEFT: Earth with IFC; $\quad$ BOTTOM RIGHT: Mars with IFC

Figure 15. Aircraft Response Doublets for Two Elevon Configuration. Lateral CG Shift. 

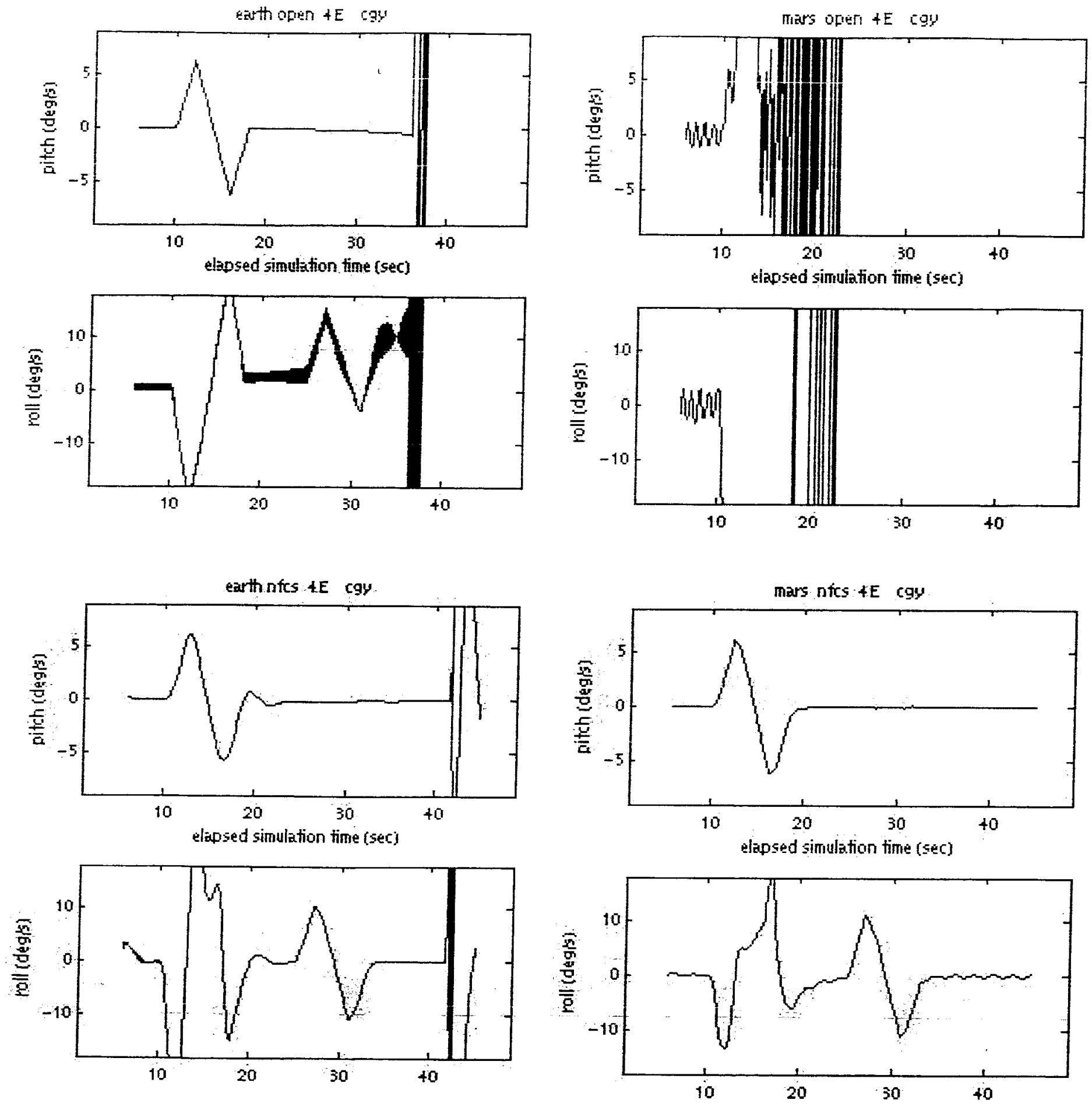

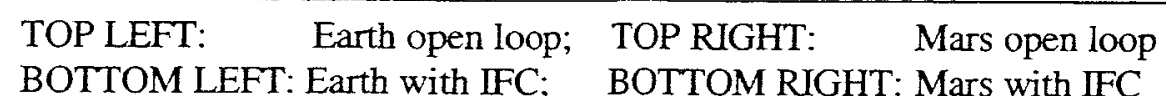

Figure 16. Aircraft Response Doublets for Four Elevon Configuration. Lateral CG Shift. 


\section{Conclusions}

Our analysis using a low-fidelity math modeling tool in conjunction with the CART3D high fidelity CFD modeler showed that even in an undamaged configuration, stability and control of this particular BEES configuration will be difficult in the Martian atmosphere without the aid of an error controller. In addition, any uncertainties will certainly require an adaptive controller. Conclusions are presented for control and design issues.

- Control issues

- Need of IFC for Mars application was established from both stability and controllability points of view.

- Additional control effectors (analytical control redundancy), such as splitting the elevators and adding rudders could improve control effectiveness and resilience in the face of damage.

- Design Issues

- CART3D provided initial verification of flyer's abilities. Use of a different wing planform to reduce drag rise at higher Mach numbers and angles-of-attack should be investigated.

\section{Recommendations}

Our recommendations for future studies related to design and control are presented next. First we present highlights of our recommendations and then present details of design trade-off issues and the outer-loop guidance and control issues.

- Design Issues

0 The drag rise for Mach $>0.7$ is quite severe even at moderate angles-of-attack. This problem could be alleviated either by avoiding the transonic regime, or preferably by modifying the design.

- Sensor locations have to be chosen to minimize the effects of the flow.

- Flyer design and the controller design should be approached simultaneously towards the goal of achieving the mission needs.

- Control issues

- Outer-loop guidance and control issues are important and were not examined in this study.

- Sensor noise/failure issues need to be examined.

- Hardware implementation of the IFC design using Field Programmable Gate Arrays (FPGA) need to be investigated.

\section{References}

1. Thakoor, S. et al, "Bioinspired Engineering of Exploration Systems for NASA and DoD", Artificial Life journai, 2002, Vol 8, Issue 4, p357-369.

2. D. D. Soccol, S. Thakoor, et al "A Utilitarian UAV design for NASA Bioinspired Flight Control Research", AlAA-2003-461.

3. Aftosmis, M.J., Berger, M.J., and Melton, J.E. ALAA 97-0196: Robust and Efficient Cartesian Mesh Generation for Component-Based Geometry - 35th AIAA Aerospace Sciences Meeting, Reno NV Jan, 1997.

4. Aftosmis, M.J., Berger, M.J. AIAA 2000-0808, A parallel multilevel method for adaptively refined Cartesian grids with embedded boundaries - 38th AIAA Aerospace Sciences Meeting and Exhibit, Reno NV Jan. 2000.

5. Totah, J. J., Kinney, D. J., Kaneshige, J. T., and Agabon, S., "An Integrated Vehicle Modeling Environment”, AIAA Paper 99-4106, 1999. 
6. Rysdyk, R., Calise. A. J., and Chen, R. T.. "Nonlinear Adaptive Control of Tiltrotor Aircraft Using Neural Networks", SAE Paper 975613. 1997.

7. Johnson. E., Calise, A., Rysdky, R., and El-Shirbiny, H., "Feedback Linearization with Neural Network Augmentation Applied to X-33 Attitude Control", AlAA Paper 2000-4157, August, 2000.

8. Miranda, L. R., Elliot, R. D., and Baker, W. M., "A Generalized Vortex Lattice Method for Subsonic and Supersonic Flow Applications", NASA CR 2865, December, 1977.

9. Stepniewski, S. and Jorgensen, C., "Accelerated Training for Large Feedforward Neural Networks", NASA TM 1998-112239, November, 1998.

10. McFarland, R. E., "Finite Element Aircraft Simulation of Turbulence", NASA TM 110437, February, 1997.

11. Rysdyk, R. T. and Calise, A. J., "Fault Tolerant Flight Control via Adaptive Neural Network Augmentation", AIAA 98-4483, August 1998. 